\title{
PRÁTICAS DE ANÁLISE DE TEXTO POR MEIO DOS FATORES DA TEXTUALIDADE
}

\author{
Manuel Benjamin Monteiro Liberal ${ }^{1}$ \\ Heliud Maia Moura ${ }^{2}$
}

\begin{abstract}
Resumo: O objetivo deste trabalho foi estudar os fatores de textualidade em produções textuais de alunos do $3^{\circ}$ ano do ensino médio de uma escola pública de Santarém/PA. Para o desenvolvimento da pesquisa, foram apresentados aos alunos alguns fatores da textualidade, propostos por Beaugrande \& Dressler (1981). Como instrumentos de análises, foram coletados 62 textos, elaborados pelos discentes. Estes textos foram estudados com base nas teorias sobre fatores da textualidade. Os resultados demonstraram que a inserção pedagógica desses fatores nas aulas de língua portuguesa favoreceu aos discentes contínua reflexão e desenvolvimento sobre sua prática escrita.
\end{abstract}

Palavras-chave: Texto; Fatores da textualidade; Ensino.

\section{Practices of textual analysis through the standards of textuality}

Abstract: The objective of this work was to study the Standards of textuality in textual productions of 3rd year high school students of a public school in Santarém / PA. For the development of the research, some of the Standards of textuality proposed by Beaugrande \& Dressler (1981) were presented to the students. As instruments of analysis, 62 texts were collected, prepared by the students. These texts were studied based on theories about Standards of textuality. The results showed that the pedagogical insertion of these Standards in the Portuguese language classes favored the students continuous reflection and development on their written practice.

Keywords: Text; Standard of textuality; Teaching.

\section{O TEXTO E OS FATORES DA TEXTUALIDADE}

Por se compreender o texto como um instrumento de interação, o presente trabalho adotará a proposta de entender a língua como atividade sociointerativa situada (ANTUNES, 2003, KOCH, 2003, KOCH; ELIAS,

\footnotetext{
'Universidade Federal do Oeste do Pará (benjamin_liberal@yahoo.com.br)

${ }^{2}$ Universidade Federal do Oeste do Pará (heliudlmm@yahoo.com.br)
}

$$
\begin{array}{lll}
\text { v. } 22 \text { n. } 50 \quad \text { p. } 330-349 \quad \text { abr/jun } 2020
\end{array}
$$


2015, MARCUSCHI, 2008). Essa posição, de acordo com Marcuschi (2008, p. 50), "toma a língua como uma atividade sociohistórica, uma atividade cognitiva e atividade sociointerativa, [...] um conjunto de práticas sociais e cognitivas historicamente situadas”, ou seja, se usa a língua para atingir/agir na sociedade.

Conceito este, distante na maioria das propostas pedagógicas presentes no ambiente escolar. Mais precisamente nas escolas públicas, o texto encontra-se longe de poder ser qualificado como "lugar de interação". Em muitos casos, o trabalho com produção textual na sala de aula nem sempre é uma realidade (SANTOS et al, 2013, p.16), o que se ocorre, na maior parte das aulas, tem sido o ensino de regras gramaticais e nomenclaturas (ANTUNES, 2003, 2005, 2010, SANTOS et al, 2013, TRAVAGLIA, 2009, 2013, NEVES 2002), ou o uso do texto como pretexto para práticas de análises que se esgotam na identificação de categorias gramaticais ou sintáticas (ANTUNES, 2005, 2010). Resultando assim, em atividades que não proporcionam ao aluno $o$ desenvolvimento de competências para a compreensão interativa, ou seja, para a participativa construção dos sentidos e das intenções presentes no texto.

Beaugrande (1997) esclarece que um texto não é formado apenas pela junção de palavras (pronunciadas ou escritas). Essa posição é acompanhada por Antunes (2010, p. 30), ao expor que "um conjunto aleatório de palavras ou de frases não constitui um texto" e, por Adam (2008, p. 107), que destaca que "um texto não deve ser observado como uma sequência de signos, mas como um conjunto de atos ou comportamentos”, isto é, o texto não constitui uma sequência de palavras, mas de ações.

Dessa forma, com base nos teóricos (ANTUNES, 2010, TRAVAGLIA, 2009, BEAUGRANDE; DRESSLER, 1981, BEAUGRANDE, 1997; KOCH; ELIAS, 2011, 2015, KOCH, 2003, MARCUSCHI, 2008) pode-se concluir, que o texto é uma construção histórica e social, no qual interagem os sujeitos sociais - locutor e interlocutor, para que, por meio dos conhecimentos linguísticos, sociais e cognitivos bem como, pela atividade interativa, negociem a produção de propostas de sentidos. É um evento comunicativo verbal: oral ou escrito, em que se encontra intenção comunicativa, independente de sua extensão.

Ao se dialogar com Beaugrande, Santos, Abreu, Marcuschi e Koch, entende-se que o que faz um texto ser um texto é a compreensão dos sentidos. $\mathrm{E}$ que essa compreensão repousa na presença dos fatores de textualidade, que pressupõem um texto comunicativo, no qual podem ser encontrados elementos 
de ligação, de sentido, retomadas de ideias, conexões que mobilizem e convirjam para compreensão de um sentido global, intenções e propósitos comunicativos, relação com outros textos.

Por isso, neste trabalho, as análises dos textos serão realizadas com base nos fatores da textualidade propostos por Beaugrande e Dressler (1981), tendose em mente que o uso e a aplicação desses fatores em sala de aula possibilitam o desenvolvimento da competência comunicativa dos alunos, em aulas de produção textual.

Chama-se atenção, ainda, ao fato de diversas leituras (em língua portuguesa) voltadas à linguística textual (MARCUSCHI, 2008, KOCH, 2004, ANTUNES, 2005, ANTUNES 2010, COSTA VAL, 2006, CAVALCANTE, 2014, KOCH; TRAVAGLIA, 2012, KOCH; ELIAS, 2015, SANTOS et al, 2013) fazerem referência aos fatores da textualidade os apontando como princípios relevantes à produção textual. Apesar disso, há poucos trabalhos que fazem menção à utilização desses fatores na sala de aula de língua portuguesa, dos quais figuram como exemplos: Fernandes (1999) e Liberal (2016).

Beaugrande e Dressler (1981) por meio de seu livro "Introduction to Text Linguistics" deram início às discussões voltadas para os fatores da textualidade. De acordo com Beaugrande e Dressler (1981, p. 3), o texto é concebido como "uma ocorrência comunicativa que reúne sete fatores de textualidade": a coesão, a coerência, a intencionalidade, a aceitabilidade, a informatividade, a situacionalidade e a intertextualidade. Sendo necessária a interação entre cada fator de textualidade para ocorrer uma comunicação eficiente. Além disso, esses autores destacam que é possível o texto não ser comunicativo, caso algum desses fatores não seja satisfeito.

Ressalta-se que para Beaugrande e Dressler (1981) a coesão e a coerência são identificadas como noções centradas no texto e os cinco demais fatores (intencionalidade, aceitabilidade, informatividade, intertextualidade e situacionalidade) como noções centradas no usuário. Já Antunes (2010) propõe como propriedade do texto, a coesão, a coerência, a informatividade e a intertextualidade. Para essa autora, a intencionalidade, a aceitabilidade e a

\footnotetext{
${ }^{3}$ A communicative occurrence which meets seven Standards of textuality. Tradução nossa.
} 
situacionalidade correspondem às condições de efetivação do texto. Em suma, ela resume os sete fatores em quatro: coesão, coerência, informatividade e intertextualidade, admitindo que os outros três sejam condições fundamentais para que os textos se concretizem.

Para exemplificar a análise de textos dos alunos de uma escola pública, com base na compreensão dos fatores da textualidade, neste trabalho serão apresentados quatro desses fatores e posteriormente suas aplicações nas análises dos textos.

\section{COESÃO}

De acordo com Beaugrande e Dressler (1981), a coesão pode ser explicada como a forma na qual os componentes da superfície textual encontram-se mutuamente conectados dentro de uma sequência textual. Para os autores, a estabilidade de um texto é sustentada por meio da continuidade de ocorrências. Os autores apresentam, ainda, nove mecanismos de coesão que contribuem para a estabilidade e "economia" textual: recorrência, paralelismo, paráfrase, proformas, elipse, tempo e aspecto, junção e perspectiva funcional da frase.

A coesão, de acordo com Koch (2004, p.35) se refere "a forma como os elementos linguísticos presentes na superfície textual se interligam, se interconectam [...] de modo a formar um 'tecido' (tessitura)”, responsável pela progressão do conteúdo informacional pretendido pelo produtor da ação verbal que está sendo posta em curso (MOURA, 2011).

De acordo com Cavalcante (2014, p. 30), a coesão corresponde à articulação entre as formas que compõem e que organizam um texto. Antunes (2010, p. 35) atribui à coesão, correspondência de natureza semântica, conferindo a ela a promoção da continuidade e da progressão do texto. Para essa autora, a coesão está relacionada aos recursos gramaticais e lexicais de encadeamento, ligação e inter-relação entre as partes (palavras, orações, períodos, parágrafos) do texto. 


\section{COERÊNCIA}

Beaugrande e Dressler (apud KOCH, 2004, p. 40) afirmam que coerência "diz respeito ao modo como os elementos subjacentes à superfície textual entram em configuração veiculadora de sentidos", concerne "aos modos nos quais os componentes do mundo textual (...) são mutuamente acessíveis e relevantes $^{4}$ (BEAUGRANDE; DRESSLER, 1981, p. 4). Beaugrande e Dressler (1981, p. 84) explicitam que um texto "faz sentido quando existe continuidade de sentidos entre o conhecimento ativado pelas expressões do texto"

Os autores destacam que essa continuidade de sentido(s) representa a base da coerência e que a ausência dessa continuidade caracteriza o que esses autores chamam de "senseless text", texto sem sentido.

Essas concepções de coerência acabam se complementando e convergindo a um ponto comum: a coerência se constrói além dos componentes linguísticos do texto, pois depende também de elementos pragmáticos e interacionais e do próprio conhecimento enciclopédico do interlocutor, que possibilita a realização de processos significativos para a interpretação.

Em outras palavras, pode-se dizer que a coerência corresponde à forma como as partes do texto estão relacionadas entre si, para manifestar produção de sentido, e para isso ela mobiliza a interação entre o conhecimento apresentado no texto e o conhecimento e experiências já detidos pelo leitor. Desse modo a coesão não detém por si o sentido do texto, mas fornece pistas para o seu entendimento e interpretação.

Ela materializa os subsídios que o leitor/interactante precisa para interpretar os propósitos comunicativos do autor. A interação é identificada como uma via de mão dupla, pois implica a participação do produtor do texto em fornecer, por meio do cotexto, trilhas que conduzam à compreensão e à

\footnotetext{
${ }^{4}$ The ways in which the components of the textual world (...) are mutually accessible and relevant. Tradução nossa.

5 A text makes sense because there is a continuity of senses among the knowledge activated by the expressions of the text. Tradução nossa.
} 
identificação de seu propósito comunicativo, e a participação do leitor que interagir por meio dessas informações e, a partir delas perseguir sentidos.

Sendo assim, percebe-se que, neste jogo de construção de sentidos o produtor do texto, para ser bem sucedido em sua produção, deve considerar a presença do outro, que a interação só terá sentido, de fato, se os caminhos que levam à interpretação estiverem pavimentados por um cotexto interligado; e, que o texto em si, apenas existe em função do parceiro (o outro).

$\mathrm{Na}$ sala de aula, muitos alunos ainda veem o professor como o "único outro”, ou seja, a única pessoa que receberá seus textos, (na maioria das vezes, com o objetivo de corrigi-los - os textos e os alunos). Isso resulta em produções textuais realizadas com tensão para obter nota ou satisfazer o único leitor que terá acesso ao texto. Dessa forma, dificilmente um aluno produzirá um texto pensando em interagir com o professor, ou com qualquer outro interlocutor.

O professor, como "primeiro" interlocutor das produções textuais, deverá ser a figura que mediará aos alunos a ideia de que há critérios que permitem acesso aos sentidos dos textos e, que esses critérios se manifestam por meio dos fatores da textualidade. Será ele que terá a responsabilidade de apresentar aos discentes a proposta de que para um texto ser um texto, este precisa atender a determinados princípios que fundamentam, constituem e costuram sua tessitura. Daí se percebe a importância do professor não simplesmente corrigir os textos dos alunos, apontando erros ortográficos, ou frases desconexas.

A partir de agora poderá ser entendido mais especificamente, por meio dos fatores intencionalidade e aceitabilidade, em que medida a relação entre o produtor e o interlocutor atuam na produção textual. Como já mencionado, no entender de Beaugrande e Dressler, a coesão e a coerência, são critérios centrados no texto, e os demais cinco fatores, abordados a partir de agora, são centrados no usuário: intencionalidade, aceitabilidade, informatividade, situacionalidade e intertextualidade.

\section{INTENCIONALIDADE}

A intencionalidade se refere ao modo pelo qual o produtor do texto utiliza o texto para alcançar seu objetivo comunicativo (persuasão, sarcasmo etc). De acordo com Beaugrande e Dressler (1981), a intencionalidade diz respeito à 
atitude do produtor do texto que, objetivando construir um texto coeso e coerente, utiliza recursos adequados para concretizar suas intenções comunicativas e alcançar um objetivo previamente planejado, "abrange todas as maneiras como os sujeitos usam textos para perseguir e realizar seus objetivos" (KOCH, 2014, p. 20).

Dependendo do objetivo do produtor do texto (alarmar, informar, ofender, persuadir), a intencionalidade manifestará na superfície do texto um potencial ilocutório que será aceito ou não pelo recebedor do texto. De forma simplificada, esse fator da textualidade se refere a o que o produtor do texto pretende com seu texto, uma vez que um texto é produzido com "uma finalidade que deve ser captada pelo leitor” (MARCUSCHI, 2008, p. 126).

\section{O LOCAL E OS SUJEITOS DA PESQUISA}

A pesquisa ocorreu na escola estadual Nossa Senhora de Aparecida, por ser esta escola local de trabalho do pesquisador, assim foi realizada intervenção em um ambiente que faz parte da realidade do professor-pesquisar, dessa forma, foi possível aplicar os conhecimentos adquiridos no curso de Mestrado PROFLETRAS, na escola pública onde o pesquisador figura como docente, cumprindo assim os próprios objetivos desse mestrado profissional: capacitar professores de Língua Portuguesa para o exercício da docência; contribuir para a melhoria da qualidade do ensino no País.

A referida escola faz parte da rede estadual de ensino e localiza-se na região Oeste do Estado do Pará. Situa-se no município de Santarém e atende a uma clientela composta, em sua grande maioria, por alunos da classe baixa, que moram em áreas distantes da escola, necessitando de transporte público para se deslocarem à instituição.

Cerca de trezentos e dezesseis alunos compõem o corpo discente da escola, distribuídos em séries que vão do sexto ano do ensino fundamental ao terceiro ano do ensino médio que funcionam no período matutino. A escola também atende a turmas de terceira e quarta etapa e, primeira e segunda EJA, que funcionam no período noturno. A média dos alunos por sala é vinte e cinco alunos. 
Na escola selecionada para pesquisa há apenas uma turma de $3^{\circ}$ ano do ensino médio. Essa turma era formada por vinte e três alunos oriundos dos bairros periféricos da cidade, e na sua maioria, de classe baixa.

Esses alunos tinham entre dezesseis e dezenove anos. Desses alunos, dois $(8,7 \%)$ faziam cursinhos pré-vestibular, oito $(34,8 \%)$ relataram já ter estudado sobre coesão e coerência. Todos $(100 \%)$ relataram nunca ter estudado textualidade. Todos $(100 \%)$ relataram não lembrar/saber nada sobre coesão e coerência. Do total de participantes, sete $(30,5 \%)$ relataram que escrevem textos apenas na escola (obrigações escolares, segundo eles), os demais (69,5\%), informaram que escrevem textos em tarefas escolares e em redes sociais (WhatsApp e Facebook), os mesmos valores (30,5\% e 69,5\%) se referem aos locais onde os alunos leem textos, o primeiro somente na escola e o segundo na escola e em ambientes virtuais. Apenas dois $(8,7 \%)$ sujeitos relataram que além de lerem nesses ambientes, costumam ler livros e revistas.

\section{PROPOSTA DE ANÁLISE DOS FATORES DA TEXTUALIDADE NOS TEXTOS DOS ALUNOS}

Durante três meses, nas aulas de língua portuguesa, 23 alunos do $3^{\circ}$ ano do ensino médio tiveram acesso a aulas nas quais textos de diversos temas, do gênero artigo de opinião eram utilizados para fomentar discussões e servir de referencial que orientariam posteriores produções escritas. Esses alunos também presenciaram exposições dos conceitos e exemplos de aplicações dos sete fatores da textualidade.

Sendo abandonada a proposta de ensino metalinguístico, os alunos presenciavam textos de diversas temáticas. Após esse contato, os alunos eram conduzidos a ativar seu conhecimento prévio sobre o tema, fazer previsões, lançar mão do conhecimento enciclopédico, identificar a intenção do escritor, apontar traços de conexões e de continuidade de sentidos.

Além disso, no decorrer das aulas, os discentes escreviam redações que, após analisadas pelos pesquisadores, eram digitadas e apresentadas por meio de slides a toda turma (mantendo o sigilo da autoria), para servir de instrumento de análise que abrangesse todos os envolvidos na aula. 
Esse modo de ensino-aprendizagem corporificou maior significância aos alunos pelo fato destes discentes estudarem elementos linguísticos em uso, por meio de materiais produzidos por eles próprios, o que proporcionava uma reflexão mais acurada.

Ao final da pesquisa, ao término dos três meses, foram coletadas mais de 60 produções textuais (da ordem do argumentar), das quais foram analisadas em sala de aula, aproximadamente, vinte, voluntariamente escritas pelos alunos do $3^{\circ}$ ano do ensino médio, que serviram como exemplo de análise textual abordada durante as aulas. Para este artigo foram selecionados dois textos como modelo de análises realizadas. Geralmente as propostas de produção textuais eram as mesmas apresentadas nas provas do ENEM dos anos 2011, 2013, 2014. Houve, ainda, uma sugestão de elaboração de texto proposta pelo Sistema Paraense de Avaliação da Educação - SISPAE 2014,

Nesse sentido, a partir de agora serão apresentados dois textos (texto \#4 e texto \#7) como modelos de análise dos fatores da textualidade. Foram selecionados para análise dos textos, os fatores da textualidade coesão, coerência e intencionalidade devido à extensão do artigo, bem como por estes representarem imediato retorno de propostas didáticas que proporcionem aos alunos desenvolvimento de sua qualidade de escrita.

Primeiramente, identifica-se que os textos pertencem à ordem do argumentar, ou seja, espera-se que os alunos manifestem em suas produções: opiniões, posicionamentos sobre problemas e argumentos que fortaleçam suas ideias. Além disso, por esses textos pertencerem ao gênero textual artigo de opinião, espera-se ainda, que eles respeitem características como: serem textos formais, que apresentem a defesa de um tema ou argumento e que possuam introdução, desenvolvimento e conclusão. 


\section{TEXTO \#04}

\section{A utilização necessaria ao usar as redes sociais}

1 Como Ǿ podemos nos deparar, as caracteristicas da sociedade e 2 delas esta no uso da tecnologia, que passou a ser um fenomeno na vida dos 3 jovens, atravéz desse sistema, a muitos utilizados, que são as redes sociais 4 pois tem influenciado na área entre o o que e publico e o privado, de facto 5 muitos jovens de nossa sociedade então vivendo em uso no mundo das 6 redes sociais.

7 Para opiniões diferentes tem se desenvolvido o uso das redes sociais. 8 A vida do jovem e vinculada as redes, pois lá pode trocar ideias, debater, 9 assimilar conhecimento em seus benefícios como o facebook, wathsapp, 10 instagran e twiter são muitas utilizados, nos que ao usalas Ǿ devemos ter 11 cautela pois requer um conhecimento sobre o publico e o privado, porém

12 Ǿ temos muitos oportunidades de aprontar cada conhecimento com redes 13 sociais.

\section{ANÁLISE DA COESÃO E DA COERÊNCIA TEXTO \#04}

De modo geral, este é um texto incoerente, uma vez que apenas com bastante esforço por parte do leitor é possível reconstruir o propósito comunicativo do escritor ou estabelecer uma relação entres as informações escritas no texto, principalmente no primeiro parágrafo. $\mathrm{O}$ título não conduz o leitor a nenhuma inferência do que poderá ser tratado no texto, além disso, não há articulação entre os parágrafos.

Logo na primeira linha, identifica-se a ocorrência de uma elipse, “Ǿ podemos”, fato também presente na décima primeira “Ǿ devemos" e na penúltima linha, "Ǿ temos”. Nesse texto específico, os termos elididos foram o pronome "nós”, facilmente recuperados pela desinência verbal.

Seguindo a análise, considerando o embaraço que causa à leitura, devido à forma como o cotexto está disposto, fica difícil identificar, de imediato, a quem se refere o elemento anafórico "delas", linha 2, mas como única possibilidade de concorrente à referente, aponto para o termo "características". A próxima remissão, realizada pelo termo "desse sistema” (linha 3), representa uma recategorização por meio de um nome genérico.

Essa remissão pode gerar dúvida ao leitor sobre qual referente esse nome genérico retoma, se ao termo "tecnologia" (anaforicamente) linha 2, ou ao 
termo "redes sociais" (cataforicamente) linha 4. Pelo crédito de coerência que se dispensa ao ler, intuitivamente compreende-se esse termo como uma catáfora, ou seja, o elemento que faz remissão ao referente "redes sociais", mesmo o termo "sistema" não estando pluralizado, assim como redes sociais, é possível por meio do conhecimento enciclopédico realizar essa relação. Essa possibilidade ressalta o fato da coesão ser suficiente, porém não necessária para que haja coerência (MARCUSCHI, 2008).

O termo rede sociais foi escrito quatro vezes pelo aluno (linhas 4, 6, 7 e 13). Esse novo referente foi apresentado inicialmente, cataforicamente como "um sistema" e repetido nas demais linhas identificadas. Considerando que a palavra "redes sociais" já seja um hiperônimo, o aluno poderia, nas linhas seis e sete, ter recategorizado este referente por meio de sinônimos ou nomes genéricos. Isso porque, entende-se que nessas duas linhas não havia necessidade de repetição e por meio da recategorização, o aluno poderia atribuir uma informação a mais ao seu referente, como por exemplo, ao invés de redes sociais, utilizar os termos "interações online, formas de interação virtual".

$\mathrm{Na}$ última linha, infere-se que o discente, ao repetir o termo estudado, relembrou ao leitor o referente já citado anteriormente. $O$ discente ainda recategoriza o termo "redes sociais" pela palavra "redes" (linha 8). Na mesma linha ocorre, o único caso de remissão anafórica por meio do advérbio locativo "lá"(dentre os trinta textos analisados), utilizado pelo aluno para substituir o local onde os jovens podem "trocar ideias, debater, assimilar conhecimento", as redes sociais.

Neste texto também estão presentes duas ocorrências de referenciação por meio dos pronomes possessivos, o primeiro, "nossa", na linha 5 e o segundo, "seus benefícios", na linha 9, que apesar de concordarem gramaticalmente com seus antecedentes, ainda assim conduzem o leitor a uma leitura truncada.

Fazendo um traçado mais específico sobre a coesão, o material linguístico apresentado na superfície textual não sinaliza laços que possibilitem o leitor unir as partes do texto, o leitor precisa se esforçar para identificar conexão entre as frases e entre os parágrafos. Apesar da presença de elementos remissivos, que de certa forma, deveriam proporcionar uma certa "economia" à leitura, não possibilitam uma retomada de ideia para em seguida progredi-la. 
O texto não apresenta avanço de ideias, o que compromete sua progressão textual, de certo modo, as informações são apresentadas de forma fragmentada, desorganizadas e sem conexão com as ideias anteriores, o que resulta em um texto com argumentos não articulados e relacionados, bem como com a coerência onerada. Como exemplos desse não avanço, bem como dessa não relação, são verificados nas frases "Como Ǿ podemos nos deparar, as caracteristicas da sociedade e delas esta no uso da tecnologia”, “(...) atravéz desse sistema, a muitos utilizados, que são as redes sociais pois tem influenciado na área entre o que e publico e o privado" e "nos que ao usalas Ǿ devemos ter cautela pois requer um conhecimento sobre o publico e o privado, porém Ǿ temos muitos oportunidades de aprontar cada conhecimento com redes sociais".

\section{ANÁLISE DA INTENCIONALIDADE TEXTO \#04}

Talvez o propósito comunicativo do discente fosse expor que "é constitutivo da sociedade atual o uso de tecnologias, e que este uso se manifesta entre os jovens, principalmente, por meio das redes sociais" (linhas 1 e 2).

Não ficou claro o que escritor pretendeu expor com a discussão "público e privado", acredita-se que o próprio aluno escritor não tenha entendido essa discussão e como ela tem sido manifesta em torno da temática "redes sociais".

Uma sugestão bem simples para auxiliar o aluno a escrever um texto que revele seu propósito comunicativo, é este aluno ser ensinado a produzir sua composição tendo em vista a seguinte pergunta: "o que eu quero dizer com esse texto?”. Por fim conclui-se que o escritor não conseguiu colocar no papel o que ele realmente queria dizer.

Para concluir esta análise, infere-se que esse texto possui termos comuns ao conhecimento compartilhado que o leitor detém, que, de certa forma, direcionando este leitor à temática "uso das redes sociais", como (tecnologia sistema - redes - Facebook - WhatsApp - Instagran - Twitter), porém, nesta produção textual, não fica estabelecida uma unidade de sentido e nem uma cooperação por parte do escritor para fazer-se compreender, deixando pistas mais claras e organizadas para o recebedor do seu texto. 
Apesar do uso de elementos que favoreçam a coesão referencial, esse texto apresenta embaraço na leitura uma vez que não há continuidade de sentido entre as frases ou articulação entre os parágrafos, o que dispersa a atenção do leitor e torna difícil perceber qual a intenção do escritor ao produzir esse texto, ou até mesmo qual o fio condutor que sustenta essa produção.

Os elementos remissivos não conduzem o leitor a uma reativação imediata dos referentes, o que obriga o recebedor a tentar estabelecer a coerência entre esses elementos, lhes atribuindo a interpretação que lhes sejam mais apropriada.

\section{TEXTO \#07}

\section{As facetas das redes sociais (virtuais)}

$\mathrm{Na}$ sociedade em que ǿ vivemos, Ǿ buscamos sempre inovar e surpreender o mundo com novas descobertas. A "bola" da vez são as redes virtuais (sociais), um brinquedo novo, grandioso e valioso, que provavelmente revolucionarar o mundo, acaba de ser contemplado o seu (1) acesso livre um direito para todos.

As redes virtuais vem se expandindo de maneira avaçaladora, dominando e modificando os hábitos, e a vida das pessoas, (2) às deixando de viver uma vida social para viver num mundo virtual, (3) onde você é o que deseja ser. Através (4) dela Ǿ conhecemos novos amigos, Ǿ compartilhamos e Ǿ debatemos, ideias, opiniões e assuntos que envolvem o mundo todo.

Não estar conectado (5) nesse novo mundo é como se você não fizesse parte (6) dessa nova era, ou (7) deste século, um ser insignificante dentre os milhares conectados pelo mundo à fora.

De fato, (8) esse novo meio nos trás muitas vantagens, mas também acaba nós expondo a perigos que nem ó imaginamos. E é (9) nesse momento que Ǿ devemos pensar até que ponto nós devemos nos expor, e como nós posicionar diante das armadilhas das redes virtuais.

As pessoas não dão importância para o que se publica, e (10) Ǿ acabam passando dos limites denegrindo não só (11) sua imagem, mas também a de outras pessoas. (12) Ǿ Julgam (13) às sem mesmo (14) as conhecerem, manchando (15) sua imagem perante a sociedade.

Portanto, antes de publicar qualquer coisa, raciocine bem, porque qualquer erro pode ser fatal, uma vez publicada, foge do nosso controle as dimensões que irão tomar, e em poucos minutos, de juiz, você se torna réu. 


\section{ANÁLISE DA COESÃO E DA COERÊNCIA TEXTO \#07}

Observa-se no texto 07 que todos os elementos nele numerados fazem remissão a outro elemento no texto. Desse modo, "seu", em (1), refere-se a "redes virtuais (sociais), "as” em (2), remete a "pessoas". Em (3), “onde” remete a "mundo virtual". Em (4), "dela faz remissão a "redes virtuais". O mesmo referente é retomado em (8). Em (5), "nesse novo mundo" refere-se a "mundo virtual. Já "dessa nova era”, em (6) remete para elementos fora do texto, ou seja, (exoforicamente) para um momento temporal que nos encontramos hoje, "moderno" em relação às eras passadas. O mesmo caso ocorre em (7), no qual "deste século" remete-se ao século XXI, não expresso no texto, mas inferível por meio do enunciado presente na linha 1, "na sociedade em que vivemos".

Em (9), "nesse momento" remete à parte do enunciado anterior. Em (10), o sujeito elíptico refere-se "as pessoas", este mesmo referente é retomado em (11), pelo pronome "seus". Em (12), não fica claro a quem se refere o elemento elidido, porém identifica-se o termo "as pessoas" como elemento potencial de referência. Em (13), (14) e (15), também não fica bem estabelecido qual é o referente textual as quais essas formas remissivas se remetem, mas por inferência pode-se atribuir a elas (13, 14 e 15), “outras pessoas”.

Todos esses elementos anteriores numerados estabelecem estruturas de coesão referencial. Como já explicado, esses elementos, presentes na superfície textual, fazem remissão a outros componentes escritos ou inferíveis no texto. Nesse texto, essas estruturas se responsabilizam pela progressão referencial (remissão a um mesmo referente), que constitui a continuidade do texto por meio da repetição (retroação) e da progressão.

As repetições presentes neste texto, retomadas anafóricas (1), (2), (3), (4), (5), (8), (10), permitem um rápido reconhecimento dos segmentos por elas retomadas, não deixando perder de vista a continuidade e a progressão das ideias apresentadas pelo discente, isso possibilita uma leitura que mantenha o leitor focalizado nos referentes introduzidos à medida que o texto progride.

Logo no primeiro parágrafo, o aluno cria uma cadeia anafórica em torno do referente "redes virtuais" por meio de recategorizações que vai ao longo do discurso costurando a construção desse referente. Essa costura inicia com a apresentação do termo "novas descobertas", linha 2, seguidos pelos vocábulos "bola da vez", "um brinquedo novo", "grandioso" e "valioso". 
Todas essas expressões manifestam a intenção comunicativa do aluno de posicionar ao leitor como este discente concebe as redes virtuais, essas escolhas trazem ao interlocutor informações importantes que revelam as crenças e as opiniões do aluno escritor, ajudando esse interlocutor na construção do sentido (do que representa rede virtual para o escritor).

Pode-se perceber que durante a leitura, o objeto do discurso, redes virtuais, aos poucos vai sendo construído e reconstruído no interior do texto por meio das descrições expressas pelo aluno: é grandioso, valioso, um brinquedo novo, revolucionário, modificador de hábitos, local de interação, um ambiente suscetível a perigos. Por meio dessas construções e reconstruções, o aluno escritor interage com o leitor proporcionado a este pistas sobre suas intenções comunicativas.

Além disso, põe-se em relevo o fato do discente repetir pelo menos seis vezes o vocábulo "mundo". O uso dessa forma nominal reiterada não "cansa" ou empobrece o texto. Pelo contrário, o discente chega a apresentar dois "mundos no texto", o virtual e o "real". De fato, nesse texto, a forma reiterada de maior significação é o termo "redes virtuais". A repetição lexical desse termo na linha 6 , no início do segundo parágrafo, contribui para a progressão textual, realizando uma conexão entre o primeiro e o segundo parágrafo.

$\mathrm{Na}$ linha 19, no quarto parágrafo a repetição lexical, do termo redes virtuais, reativa na memória do interlocutor o referente momentaneamente desfocalizado, enquanto outros referentes e declarações eram introduzidas e desenvolvidas.

De volta à linha 7 , a frase "As redes virtuais vem se expandindo de maneira avaçaladora, dominando e modificando os hábitos, e a vida das pessoas, às deixando de viver uma vida social para viver num mundo virtual”. Nesse enunciado, o texto apresenta o pronome -as, como uma anáfora que facilmente é reconhecida pelo leitor como um elemento textual que retoma o referente pessoas, pelo fato deste recebedor, por meio do seu conhecimento de mundo entender que "quem possui hábitos sociais" são "pessoas", e não "redes sociais" ou "vida de pessoas". Nesse caso, observa-se que conhecimento enciclopédico que o leitor possui desempenhou papel decisivo na escolha do possível referente à predicação que se seguiu. 


\section{ANÁLISE DA INTENCIONALIDADE TEXTO \#07}

$\mathrm{Na}$ frase “(...) um brinquedo novo, grandioso e valioso, que provavelmente revolucionarar o mundo, acaba de ser contemplado o seu acesso livre um direito para todos”. Percebe-se que o aluno tinha claro em sua mente o que ele queria escrever, porém, no momento de repassar essas informações para o papel, houve uma pequena quebra, que aqui pode ser identificado como "problema de suficiência de dados" (COSTA VAL, 2000).

Faltaram informações, que tornem mais claros os argumentos desenvolvidos pelo aluno. Por exemplo. Não fica claro para o interlocutor quando foi contemplado o acesso livre, o seria um acesso não livre. Por meio da inferência e do conhecimento enciclopédico, se consegue entender que anteriormente as redes virtuais não podiam ser acessadas por todas as pessoas, mas atualmente, elas estão disponíveis ao acesso de quem puder fazer uso desse meio de comunicação.

A quebra da linearidade da leitura ocorre devido ao não paralelismo da sentença, uma vez que o projeto comunicativo do aluno na frase em análise possibilita a recuperação do seguinte sentido: "que as redes virtuais tiveram, recentemente, seu acesso livre autorizado e que este acesso é um direito para todos”, porém a forma como essa informação foi disposta no cotexto embaraçou a leitura, sendo necessário um rearranjo dos elementos linguísticos na superfície textual.

De modo geral, percebe-se que em muitos casos, as informações estão claras na mente dos alunos que escrevem o texto, todavia no momento em que estão escrevendo suas produções acabam "desconsiderando" que o interlocutor não possui todas as informações que esses alunos escritores tinham durante a produção textual.

Esse descuido pode levar os discentes escritores a não escreverem informações importantes à compreensão do texto ou deixarem lacunas no interior do texto, que não serão possíveis interpretar apenas com a inferência. Por isso, os discentes precisam considerar, que o texto por eles produzidos deve conter todas as informações necessárias que revelem as suas intenções comunicativas.

De modo geral, o discente consegue apresentar conceitos oportunos à construção e reconstrução do objeto do discurso "redes virtuais", propondo ao 
leitor considerações não previsíveis, que possibilitam ao recebedor do texto, ao ler, apoiar-se no que ele já conhece para processar as novas informações.

Por exemplo, ao observar a frase na linha 20: "as pessoas não dão importância para o que se publica, e acabam passando dos limites denegrindo não só sua imagem, mas também a de outras pessoas", identifica-se que o escritor não especifica quem publica, o que significa publicar, de que forma se passa dos limites ou como se pode denegrir a imagem de alguém por meio das redes virtuais.

Porém o leitor, por meio do conhecimento enciclopédico, processa esse trecho com base no que já dispõe sobre interação virtual, confrontado esse saber com as novas informações apresentadas no texto: conseguindo assim processar o que o escritor escreveu e reconstruir os sentidos por ele almejado: que as pessoas não dão importância para o que elas mesmas publicam, e que algumas dessas publicações (fotos, textos, comentários), denigrem a imagem das pessoas (em geral) ou de outros usuários desses meios de comunicação.

\section{CONSIDERAÇÕES FINAIS}

A análise textual é um tema que ainda necessita de bastante aprofundamento por parte dos professores de língua portuguesa. Apenas dizer que os textos dos alunos não estão bons, que não possuem coesão ou coerência, ou que os discentes não sabem escrever não irá auxiliar a esse aluno melhorar sua competência textual.

Para isso, o professor precisa ter em mente que o ensino do "texto escolar" pode (deve) proporcionar ao discente habilidades para operar como textos fora da escola, uma vez que o uso de textos constitui uma prática social. Como o aluno do terceiro ano já domina o uso do código, uma das tarefas do professor passa a ser melhorar a qualidade de leitura e de escrita que o discente possui desse código.

Para que isso ocorra, primeiramente, o docente deve estar em continua formação, buscando além dos diversos exercícios mecânicos dos livros didáticos, embasamentos mais sólidos para subsidiar o modo de sua análise textual. Como já falado, estudar coesão e coerência textual pode representar ir de encontro a um terreno movediço, no qual a responsabilidade maior será do 
professor em apresentar aos alunos, textos nos quais esses fatores da textualidade estejam presentes, ou não estejam presentes.

É dele também a responsabilidade, em garantir ao aluno o acesso aos elementos que tornam um texto coeso ou coerente, pois esses elementos estarão explícitos em práticas sociais que utilizam a linguagem, sendo, assim, importante para qualquer indivíduo o acesso a esse conhecimento.

Não se pretendeu aqui cristalizar um modelo de análise de texto, para não obscurecer a riqueza de diversidade de análises cabíveis, mas da maneira como foram analisados os textos, acredita-se ter sido possível apresentar uma proposta de análise plausível sobre o modo como os alunos mobilizam conhecimentos referentes à língua e a textos.

Ressalta-se que utilizar o ensino de texto (dos mais diversos gêneros) não é a solução para o professor de língua portuguesa para melhorar a qualidade de leitura e de escrita, em fim, a qualidade interativa dos alunos, mas ele é uma das possibilidades. Por meio das análises dos textos foi possível perceber que os alunos ao terem acesso aos textos do gênero estudado, e, principalmente ao terem acesso ao estudo dos textos escritos por eles mesmos, se auto-analisavam e refletiam sobre sua própria prática escrita e discursiva.

Eles percebiam que em seus textos, a materialidade linguística por eles apresentadas, por vezes não dava conta de orientar o(s) leitor(es) ao propósito que eles tinham intencionado, inicialmente, em suas mentes. Eles percebiam que a coerência não se encontra engessada no texto, não é algo que depende exclusivamente do escritor, ou exclusivamente do leitor, mas é construída por meio da "interação" entre o escritor-texto-leitor. Dessa forma, os alunos passaram a perceber que para escrever o texto, o interlocutor é fundamental, pois interfere nas escolhas lexicais, bem como nas escolhas do modo como as informações estarão materializadas no texto.

\section{REFERÊNCIAS}

ADAM, J. M. A linguística textual: introdução à analise textual dos discursos. São Paulo: Cortez, 2008. 
ANTUNES, Irandé. Aula de português: encontro \& interação. São Paulo: Parábola Editorial, 2003.

ANTUNES, Irandé. Lutar com as palavras: coesão e coerência. São Paulo: Parábola Editorial, 2005.

ANTUNES, Irandé. Análise de textos: fundamentos e práticas. São Paulo: Parábola Editorial, 2010.

BEAUGRANDE, R. New Foundation for a Science of Text and Discourse: cognition, communication and the freedom of access to knowledge and Society. Norwood, New Jersey: Ablex, 1997. Disponível em http://ebookfinder.com/ebook.php?id=w7flIw2TrbsC. Acesso em: 21 dez. 2015.

BEAUGRANDE, R. A, \& DRESSLER, W. U. Introduction to Text Linguistics. London: Longman, 1981.

CAVALCANTE, Mônica Magalhães. Os sentidos do texto. São Paulo: Contexto, 2014.

COSTA VAL, Maria da Graça. Repensando a textualidade. In: AZEREDO, J. C (org.) Língua portuguesa em Debate: conhecimento e ensino. Petrópolis: Vozes, 2000.

COSTA VAL, Maria da Graça. Redação e Textualidade. $3^{\underline{a}}$ Ed. São Paulo: Martins Fontes, 2006.

FERNANDES, Nohad Mouhanna. $O$ ensino/aprendizagem da produção textual na quinta série do ensino fundamental: análise do processo e do produto. 1999. 222 f. Dissertação (Mestrado em Linguística Aplicada) Universidade Estadual de Maringá, Maringá, 1999. Disponível em www.ple.uem.br/defesas/pdf/nmfernandes.pdf. Acesso em: 05 maio 2015.

KOCH, I. G. V. Desvendando os segredos do texto. 2 ed. São Paulo: Cortez, 2003.

KOCH, I. G. V. Introdução à linguística textual: trajetória e grandes temas. São Paulo: Martins Fonseca, 2004.

KOCH, I. G. V.; ELIAS, V. M. Ler e compreender os sentidos do texto. $3^{3}$ ed. São Paulo: Editora Contexto, 2011. 
KOCH, I. G. V.; ELIAS, V. M. Ler e escrever: estratégias de produção textual. $2^{\underline{a}}$ ed. São Paulo: Editora Contexto, 2015.

KOCH, I. G. V.; TRAVAGLIA, L. C. A Coerência Textual. 18. ed. São Paulo: Contexto, 2012.

LIBERAL, M. B. Práticas de produção textual: análise dos fatores de textualidade evidenciados nas produções textuais de alunos do $3^{\circ}$ ano do ensino médio de uma escola pública de Santarém. 2016. 113 fls. Dissertação (Mestrado Profissional em Letras). Universidade Federal do Oeste do Para - UFOPA, Santarém, 2016.

MARCUSCHI, Luiz Antônio. Produção Textual: análise de gêneros e compreensão. São Paulo: Parábola editorial, 2008.

MOURA, H. L. M. Aspectos da coesão referencial em textos narrativos míticos: $o$ caso da anáfora indireta. Anais do SETA (UNICAMP), v. 5, p. 428-439, 2011.

NEVES, Maria Helena. A Gramática: história, teoria e análise, ensino. São Paulo: Editora Unesp, 2002.

SANTOS, Leonor Werneck; RICHE, Rosa Cuba; TEIXEIRA, Cláudia Souza. Análise e produção de textos. São Paulo: Contexto, 2013.

TRAVAGLIA, Luiz Carlos. Gramática e interação: uma proposta para o ensino de gramática. 14. ed. São Paulo: Cortez, 2009.

TRAVAGLIA, Luiz Carlos. Na trilha da Gramática: conhecimento linguístico na alfabetização e letramento. São Paulo: Cortez, 2013.

Recebido em 25/07/2019

Aprovado em 29/02/2020 